\title{
Enhanced Cortical Extracellular Levels of Cholecystokinin-Like Material in a Model of Anticipation of Social Defeat in the Rat
}

\author{
Chrystel Becker, ${ }^{1}$ Marie-Hélène Thiébot, ${ }^{1}$ Yvan Touitou, ${ }^{2}$ Michel Hamon, ${ }^{1}$ François Cesselin, ${ }^{1,2}$ and \\ Jean-Jacques Benoliel ${ }^{1,2}$
}

1/nstitut National de la Santé et de la Recherche Médicale U. 288, NeuroPsychoPharmacologie Moléculaire, Cellulaire et Fonctionnelle, and 2Service de Biochimie Médicale, Faculté de Médecine Pitié-Salpêtrière, 75634 Paris Cedex 13, France

The involvement of cholecystokinin (CCK) in the mechanisms of stress and/or anxiety was assessed by in vivo microdialysis in rats subjected to a social stress paradigm. During the initial 30 min period of each conditioning session, a male Sprague Dawley rat (intruder) was placed in a protective cage inside the cage of a male Tryon Maze Dull rat (resident), allowing unrestricted visual, olfactory, and auditory contacts but precluding close physical contact between them. During the following $15 \mathrm{~min}$ period, both the protective cage and the resident were removed (nondefeated intruders) or only the protective cage was removed allowing the resident to attack the intruder (defeated rats). This procedure was repeated once daily for $4 \mathrm{~d}$. On the fifth day, a guide cannula was implanted into the prefrontal cortex of intruders. During a single 30 min test session, performed $4 \mathrm{~d}$ later, intruders were subjected to only the $30 \mathrm{~min}$

A large body of evidence supports the proposal that cholecystokinin (CCK) plays an important role in the neurobiological mechanisms of stress and/or anxiety. To date, two types of specific receptors, named CCK-A and CCK-B, are known to mediate the actions of this neuropeptide. Although CCK-A receptors are found primarily in the periphery, they are also present in a few brain areas (area postrema, interpeduncular nucleus, and nucleus of the solitary tract). On the other hand, CCK-B receptors are almost exclusively expressed in the CNS (Noble et al., 1999). Sulfated CCK-8 (CCK-8S) and other CCK-B receptor agonists, such as the tetrapeptide CCK-4, possess anxiogenic-like properties in various species (van Megen et al., 1996). In humans, administration of CCK-4 has been reported to provoke attacks in panic subjects (Bradwejn et al., 1990) and healthy volunteers (de Montigny, 1989). Conversely, selective CCK-B receptor antagonists produced anxiolytic-like effects in various animal paradigms (such as plus-maze and social interaction) (van Megen et al., 1996; Shlick et al., 1997; Daugé and Léna, 1998) and prevented

Received Aug. 10, 2000; revised Oct. 2, 2000; accepted Oct. 9, 2000.

This research was supported by grants from Institut National de la Santé et de la Recherche Médicale and Bristol-Myers Squibb Foundation (Unrestricted Biomedical Research Grant). C.B. was recipient of a fellowship from the Ministère de l'Education Nationale, de l'Enseignement Supérieur et de la Recherche during performance of this work. We are grateful to Dr. D. Le Bars and Dr. C. Spielewoy for helpful discussions, B. Zeau for excellent technical assistance, and pharmaceutical companies for generous gifts of buspirone (Bristol-Myers Squibb, Wallingford, CT) and CI-988 (Parke-Davis, Ann Arbor, MI).

Correspondence should be addressed to Jean-Jacques Benoliel, Institut National de la Santé et de la Recherche Médicale U. 288, NeuroPsychoPharmacologie Moléculaire, Cellulaire et Fonctionnelle, Faculté de Médecine Pitié-Salpêtrière, 75634 Paris Cedex 13, France. E-mail: benoliel@ccr.jussieu.fr.

Copyright (C) 2001 Society for Neuroscience $0270-6474 / 01 / 210262-08 \$ 15.00 / 0$ protected confrontation to the resident. Anxiety-like behavior (immobility, ultrasonic vocalizations, and defensive postures), associated with an increase (approximately $+100 \%$ above baseline) in cortical outflow of CCK-like material (CCKLM), were observed in defeated intruders. Pretreatment with diazepam (5 $\mathrm{mg} / \mathrm{kg}$, i.p.), but not buspirone (0.5-2 mg/kg, i.p.), prevented both the anxiety-related behavior and CCKLM overflow. The selective CCK-B receptor antagonist $\mathrm{Cl}-988$ (2 $\mathrm{mg} / \mathrm{kg}$, i.p.) reduced the anxiety-like behavior without affecting the increase in CCKLM outflow. These data indicate that anticipation of social defeat induces a marked activation of cortical CCKergic neurons associated with anxiety-related behaviors in rats.

Key words: CCK; in vivo microdialysis; frontal cortex; anticipation of social defeat; anxiolytics; stress; anxiety

CCK-4 from inducing panic attacks in humans (Bradwejn et al., 1994).

CCK-containing neurons are widely distributed throughout the brain, especially in corticolimbic structures such as the frontal cortex (Beinfeld et al., 1981; Marley et al., 1984; Iadarola et al., 1989). Increases in the tissue concentrations of CCK and the density of CCK receptors have been consistently reported in the cerebral cortex of rats subjected to anxiogenic situations (Siegel et al., 1984; Brodin et al., 1989; Harro et al., 1990, 1992; Vasar et al., 1993). Additionally, cortical extracellular CCK concentrations increased in rats subjected to stressful or anxiogenic-like stimuli (Nevo et al., 1996; Becker et al., 1999). However, the experimental paradigms used in these studies did not permit the assessment of a causal link between increased cortical CCK outflow and behavior. The aim of the present study was to fill in this gap by quantifying both the cortical CCK release and the behavior of rats subjected to a relevant stressful paradigm.

Social defeat, which results from exposure of a male rat to social agonistic encounters, is a situation frequently met in the natural habitat (Koolhaas et al., 1997). Convergent data have demonstrated that a social-aggressive encounter induces physiological evidence of stress, including elevations in plasma ACTH and corticosterone levels, increased heart rate and body temperature, and altered activity of neurochemically identified systems in brain (Miczek et al., 1991; Albonetti and Farabollini, 1994; Tornatzky and Miczek, 1994; Tidey and Miczek, 1996; Keeney and Hogg, 1999). Thus, this procedure can be considered as an appropriate model for the analysis of changes associated with social stress in rats.

The present paradigm was designed to study concomitantly the 
conditioned behavioral and biochemical consequences of the anticipation of social defeat. This was achieved by repeatedly subjecting experimental intruder rats to the threats by an aggressive conspecific resident, before being physically attacked and defeated. The effects of clinically efficient or putative anxiolytics on both behavioral parameters and cortical CCK release were examined under these experimental conditions.

\section{MATERIALS AND METHODS}

\section{Animals}

Male Sprague Dawley rats (Centre d'Élevage R. Janvier, Le Genest-StIsle, France), weighing 250-300 gm, served as the experimental "intruder" animals. They were placed in individual cages $(45 \times 25 \times 17 \mathrm{~cm})$ for $10 \mathrm{~d}$ before the beginning of the experiments. Male Tryon Maze Dull S3 (TMD) rats (University of Limburg, Maastricht, The Netherlands), weighing 500-600 gm, served as "resident" rats in agonistic encounters. They were housed singly from weaning (at 3 weeks of age) in appropriate cages $(45 \times 45 \times 17 \mathrm{~cm})$. TMD rats are known as being spontaneously territorially aggressive animals and thereby dominant against intruders (Koolhaas et al., 1990). Ten TMD rats were used for the whole series of experiments performed in these studies. All animals were kept under controlled environmental conditions $\left(22 \pm 1^{\circ} \mathrm{C}, 60 \%\right.$ relative humidity, $12 \mathrm{hr}$ light/dark cycle, food and water ad libitum). Procedures involving animals and their care were all conducted in conformity with the institutional guidelines that are in compliance with national and international laws and policies (council directive \#87-848 from the Ministère de l'Agriculture et de la Forêt, Service Vétérinaire de la Santé et de la Protection Animale).

\section{Social defeat}

Procedure. The behavioral procedure consisted of four daily conditioning sessions and one test session that involved the same pairs of residents and intruders. The $45 \mathrm{~min}$ conditioning sessions were divided into two consecutive periods. During period I (30 min), intruders were placed singly in a protective cage without cover $(25 \times 25 \times 30 \mathrm{~cm})$ inside the resident home cage. The resident home cage had no cover and was surrounded by a $100-\mathrm{cm}$-high wire-mesh enclosure $(45 \times 45 \mathrm{~cm})$. The protective cage allowed unrestricted visual, auditory, and olfactory contacts with the resident but precluded close physical contact (Fig. 1). During period II $(15 \mathrm{~min})$, the protective cage was removed. After the fourth conditioning session, i.e., the fifth day, intruders were implanted with a guide cannula (see below). Four days later, the experimental intruders implanted with the microdialysis probe (see below) were subjected to a single test session that consisted of a 30 min protected confrontation only.

Intruder rats were divided into two groups. During period II of each session, the resident was either present, allowing physical confrontation with the intruder (defeated intruders), or removed, while the intruder had access to the entire resident home cage (nondefeated intruders). Therefore, the nondefeated intruders were never physically attacked and defeated by the resident.

Behavioral quantification. The duration of immobility and $22 \mathrm{kHz}$ ultrasonic vocalizations (USV) and the total number of rearings, wallclimbings (i.e., ascending the protective wire-mesh partition), and defensive-submissive postures (i.e., upright posture) were directly observed during period I of the four conditioning sessions and during the test session. USV were detected using a Batbox III (CEBA, Le Verdier, France), and behaviors were measured by two experienced observers who were blind to the treatment conditions.

Behavioral data were analyzed by two-way (subjects, sessions or subjects, drugs) ANOVAs followed, as appropriate, by pairwise comparisons using the Dunn's $t$ test with the error variance term from ANOVAs.

\section{Microdialysis}

To estimate the in vitro recovery of CCK-like material (CCKLM), dialysis membrane was immersed at room temperature in an artificial CSF (aCSF) containing 0.25 or $0.50 \mathrm{ng} / \mathrm{ml}$ CCK-8S (Bachem, Bubendorf, Switzerland) and continuously perfused with aCSF at $3.0 \mu \mathrm{l} / \mathrm{min}$. Two fractions (corresponding to $90 \mu \mathrm{l}$ each, $30 \mathrm{~min}$ ) were collected for each probe at each concentration of CCK-8S. The collected fractions, as well as $90 \mu \mathrm{l}$ aliquots of the original solutions, were assayed for their CCKLM content by the radioimmunoassay (RIA) procedure described below. The relative recovery of a probe was calculated as the percentage

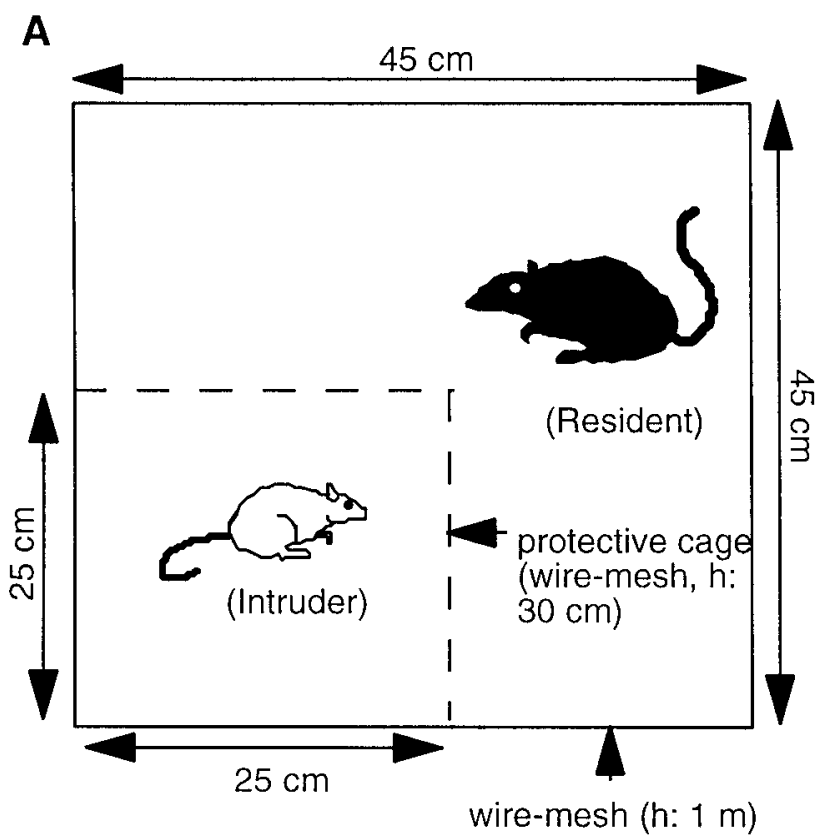

B

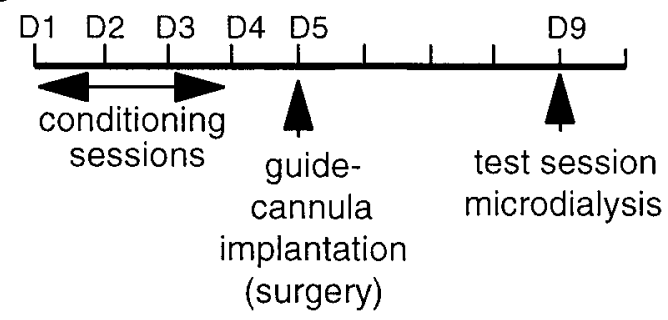

Figure 1. Social defeat stress procedure. $A$, Conditioning sessions. During period I (30 $\mathrm{min})$, the intruder was placed in a protective cage inside the home cage of resident. The protective cage allowed unrestricted visual, auditory, and olfactory contacts with the resident but precluded close physical contact. Then the protective cage was removed, allowing the resident to attack the intruder (period II, $15 \mathrm{~min}$ ). $B$, The experimental procedure consisted of four daily conditioning sessions (D1-D4) and one test session $(D 9)$ that involved the same pairs of residents and intruders. A microdialysis guide cannula was implanted on day 5. On day 9 in the course of the microdialysis study, intruders were subjected to a single test session that consisted of a $30 \mathrm{~min}$ protected confrontation to resident (period I only).

of CCKLM quantified in the microdialysates over that present in the original solution. For the two CCK-8S concentrations tested, this ratio was constant: $8.2 \pm 0.4 \%$ (mean $\pm \mathrm{SEM} ; n=22$ ). When the bath concentration of CCK-8S was changed from 0.25 to $0.50 \mathrm{ng} / \mathrm{ml}$, equilibrium was reached within the $30 \mathrm{~min}$ collection period after this change.

Twenty-four hours after the fourth conditioning session, intruders were anesthetized with chloral hydrate $(375 \mathrm{mg} / \mathrm{kg}$, i.p.) and positioned in a stereotaxic frame (David Kopf Instruments, Tujunga, CA). The skull was exposed, and a $1 \mathrm{~mm}$ diameter hole was drilled for the descent of a stainless steel guide cannula (CMA/12; outer diameter, $0.7 \mathrm{~mm}$; CMA Microdialysis, Stockholm, Sweden) with a "dummy probe." Descent was made down to the following coordinates for the tip of the guide cannula just above the frontal cortex: anteroposterior, $+2.7 \mathrm{~mm}$ from bregma; lateral, $-1.7 \mathrm{~mm}$ from bregma; height, $-0.8 \mathrm{~mm}$ from the skull (Paxinos and Watson, 1986). The cannula was then secured with dental cement to the skull, and the skin was sutured. Animals were allowed to recover from the surgery in individual cages for $4 \mathrm{~d}$ before the microdialysis experiment.

The day before the experiment, rats were placed in a Plexiglas microdialysis bowl (35 cm in diameter) with access to food and water ad 
libitum. The next morning, the dummy probe was removed, and a microdialysis probe (CMA/12; cutoff, 20,000 Da; outer diameter, 0.5 $\mathrm{mm} ; 2 \mathrm{~mm}$ in length; CMA Microdialysis) was introduced into the guide cannula so as to protrude by $2 \mathrm{~mm}$ into the frontal cortex (Nevo et al., 1996). The probe was continuously perfused at a flow rate of $3.0 \mu \mathrm{l} / \mathrm{min}$ with aCSF (in mM: $146 \mathrm{NaCl}, 3.0 \mathrm{KCl}, 1.2 \mathrm{CaCl}_{2}, 1.0 \mathrm{MgCl}_{2}, 1.9$ $\mathrm{Na}_{2} \mathrm{HPO}_{4}$, and $0.1 \mathrm{NaH}_{2} \mathrm{PO}_{4}$, final pH 7.4) supplemented with bovine serum albumin (BSA) [0.025\% w/v (Sigma, St. Louis, MO)] and peptidase inhibitors $[0.03 \%$ w/v, bacitracin (Janssen, Geel, Belgium) and $0.1 \%$ w/v, polypep (Sigma)]. To allow dialysis to reach steady state around the membrane probe, perfusion was performed for $90 \mathrm{~min}$ (washout period) before collection of the first fraction (Nevo et al., 1996). In all experiments, 11 fractions of $90 \mu \mathrm{l}$ (each corresponding to $30 \mathrm{~min}$ of perfusion) were collected at $0^{\circ} \mathrm{C}$ and then immediately frozen at $-30^{\circ} \mathrm{C}$ until the determination of their CCKLM content using the RIA procedure described below.

During the microdialysis procedure, $118 \mathrm{~min}$ after collection of the first fraction, i.e., 2 min before collecting the fifth fraction, intruders (either defeated or nondefeated) were subjected to the behavioral test session. Each rat was gently moved to the protective cage placed inside the usual resident home cage for the $30 \mathrm{~min}$ test session and then back to the microdialysis bowl. This was done without having to detach the swivel arm. Thus, during the microdialysis procedure, intruders were threatened, but not defeated, by the resident.

At the end of the experiment, animals were deeply anesthetized with chloral hydrate and decapitated. Brains were removed and immediately frozen in isopentane cooled by dry ice. Placement of microdialysis probes was verified by histological examination. When the probe was incorrectly placed, the corresponding results were discarded (in only 2 of the 73 intruders used in the studies).

Drugs and treatments. The benzodiazepine receptor agonist diazepam (5 mg/kg; Hoffmann-La Roche, Basel, Switzerland), the selective CCK-B receptor antagonist CI-988 [2 mg/kg; Parke-Davis, Ann Arbor, MI (Hughes et al., 1990)], or the $5-\mathrm{HT}_{1 \mathrm{~A}}$ receptor agonist buspirone $[0.5,1.0$, and $2.0 \mathrm{mg} / \mathrm{kg}$; Bristol-Myers Squibb, Wallingford, CT) (Hamon, 1997)], were administered intraperitoneally to the intruder $30 \mathrm{~min}$ before its protected introduction into the resident home cage. The benzodiazepine receptor antagonist flumazenil $[10 \mathrm{mg} / \mathrm{kg}$, i.p.; Hoffmann-La Roche (Hunkeler et al., 1981)] was injected 5 min before the administration of diazepam. Buspirone was diluted in saline $(0.9 \% \mathrm{w} / \mathrm{v} \mathrm{NaCl})$. Diazepam, flumazenil, and CI-988 were prepared as a suspension in acacia gum in distilled water. Intruders that received vehicle $(3 \mathrm{ml} / \mathrm{kg})$ were treated according to the same protocol.

$C C K L M$ radioimmunoassay. The buffer used for preparing $\left[{ }^{125} \mathrm{I}\right] \mathrm{hu}-$ man gastrin solution $(2000 \mathrm{Ci} / \mathrm{mmol}$; CIS Bio International, Gif-surYvette, France) and charcoal suspension was $50 \mathrm{~mm}$ barbital-HCl, pH 8.5 , containing $1 \mathrm{gm} / 1$ sodium azide and $10 \mathrm{~mm} \mathrm{MgCl} 2$. The anti-CCK-8 antiserum was obtained in a rabbit injected repeatedly with CCK-8 coupled to thyroglobulin by glutaraldehyde (Studler et al., 1981). For the measurement of CCKLM in microdialysates, $90 \mu$ fractions were incubated with $100 \mu \mathrm{l}$ of an anti-CCK antiserum solution [in barbital-HCl buffer containing $3.75 \mathrm{gm} / 1 \mathrm{BSA}$; 1/1,500,000 final dilution (Benoliel et al., 1992)] and $50 \mu \mathrm{l}$ of barbital-HCl buffer. After a $48 \mathrm{hr}$ incubation at $4^{\circ} \mathrm{C}, 50 \mu \mathrm{l}$ of the $\left[{ }^{125} \mathrm{I}\right]$ gastrin tracer solution (corresponding to $2000-$ $2500 \mathrm{cpm}$ ) was added, and incubation proceeded for an additional 20-24 hr. The assay was stopped by adsorbing the free tracer onto active dextran T70-coated charcoal (4 and $40 \mathrm{gm} / 1$, respectively, in the barbital$\mathrm{HCl}$ buffer containing $10 \%$ horse serum; $1 \mathrm{ml}$ of the suspension per tube). The tubes were immediately centrifuged at $6000 \times g$ for $10 \mathrm{~min}$ at $4^{\circ} \mathrm{C}$, and the radioactivity in the supernatants was estimated by gamma spectrometry. Standard curves were prepared from RIAs of standard solutions of $0.5-50 \mathrm{pg} /$ tube of authentic CCK-8S in $50 \mu \mathrm{l}$ of the barbital$\mathrm{HCl}$ buffer supplemented with BSA. These aliquots were mixed with 90 $\mu \mathrm{l}$ of $\mathrm{aCSF}$ and $100 \mu \mathrm{l}$ of the antiserum dilution, and RIAs then proceeded as described above. The detection limit of the assay was 0.75 pg of CCK-8S per tube, and half displacement of $\left[{ }^{125} \mathrm{I}\right]$ gastrin bound to antibodies was obtained with $\sim 10 \mathrm{pg}$ of the peptide.

Under these RIA conditions, the cross-reactivity was $233 \%$ with nonsulfated CCK-8, 204\% with gastrin, 31\% with CCK-7S, $26 \%$ with nonsulfated CCK-7, 25\% with CCK-5, 11\% with CCK-33, and 1\% with $\mathrm{CCK}-4$, and was undetectable with rat $\alpha$-calcitonin gene-related peptide (up to $2.5 \mu \mathrm{g} /$ tube) compared with $100 \%$ for synthetic CCK-8S.

The CCKLM content of each fraction was expressed as CCK equivalents, i.e., the amount of authentic CCK-8S producing the same displacement of the radioiodinated tracer bound to anti-CCK antibodies as the endogenous material. These values were not corrected for probe recovery calculated from in vitro experiments with authentic CCK-8S. The effects of treatments were assessed by expressing the levels of CCKLM in each fraction collected after the treatment as a percentage of the mean levels of the peptide in the first three fractions collected immediately after the washout period. CCKLM in each fraction was compared with baseline level using paired Student's $t$ test (two-tailed). Comparison between treated versus control groups for each fraction was made using one-way (drug) ANOVA followed, as appropriate, by the Dunn's $t$ test with the error variance term from ANOVA.

\section{RESULTS \\ Motor and social behavior of intruders during the four conditioning sessions of repeated defeat}

During period I of the first conditioning session, i.e., before the first defeat episode, the intruders displayed high levels of activity as indicated by numerous rearings, wall-climbings, and short immobility duration (Fig. 2A). USV and defensive-submissive postures were absent. During period II, when the protective cage was removed, intruders were immediately attacked and defeated by the residents. Defeat was indicated by full submissive posture, with the intruder laying motionless on its back with ventral surface exposed to the resident. The submissive postures seemed to reduce or suppress the resident aggressive behavior. Indeed, a total of three to four attacks ( $<10 \mathrm{sec}$ each) only occurred during the $15 \mathrm{~min}$ period II, and intruders were only exceptionally wounded. These animals (only 3 of the 73 intruders used in these studies) were not included in the data reported herein.

During period I of the next three conditioning sessions (days $2-4$ ), the defeated intruders were significantly less active (reduction of rearings and wall-climbings) than on the first session. In addition, they displayed defensive-submissive postures and emitted USV. These behaviors developed progressively over the successive sessions. The values of immobility, USV, and rearings measured during the fourth session were significantly different from those recorded during the second session.

In contrast, in nondefeated intruders, none of the behavioral parameters significantly varied during the four conditioning sessions (data not shown). In particular, on the fourth session, these animals displayed a lower level of immobility, a larger number of rearings and wall-climbings compared with defeated intruders, and no defensive-submissive postures or USV. Indeed, the values of all these parameters were not significantly different from those measured on the first conditioning session in the to-be defeated intruders.

\section{Motor and social behavior of intruders during the microdialysis test session}

Compared with behavioral parameters quantified during period I of the fourth conditioning session, there were no significant variations in those recorded during the microdialysis (fifth) test session (Fig. 2, compare $A, B$ ). During the 30 min observation period, this behavior consisted primarily of immobility (session 4, $23.81 \pm 0.99$ min vs session $5,25.73 \pm 1.51$ min; means $\pm \mathrm{SEM}$; $n=8$; NS), USV (25.21 \pm 0.74 vs $24.77 \pm 1.01 \mathrm{~min} ; \mathrm{NS})$, defensive-submissive postures (13.75 \pm 1.53 vs $9.40 \pm 1.57$; NS $)$, rearings $(5.57 \pm 1.16$ vs $5.40 \pm 1.21$; NS), and wall-climbings $(0.39 \pm 0.24$ vs $0.00 \pm 0.00$; NS). These five behavioral parameters recorded during the test session were significantly different from those quantified in nondefeated intruders $(n=6)$ : immobility, $4.25 \pm 1.35 \mathrm{~min}$; numbers of rearings, $17.21 \pm 2.82$; wallclimbings, $16.63 \pm 1.14$; no USV and no submissive-defensive postures (Fig. $2 B$ ). The latter values were not significantly different from those measured in the same animals on the fourth 

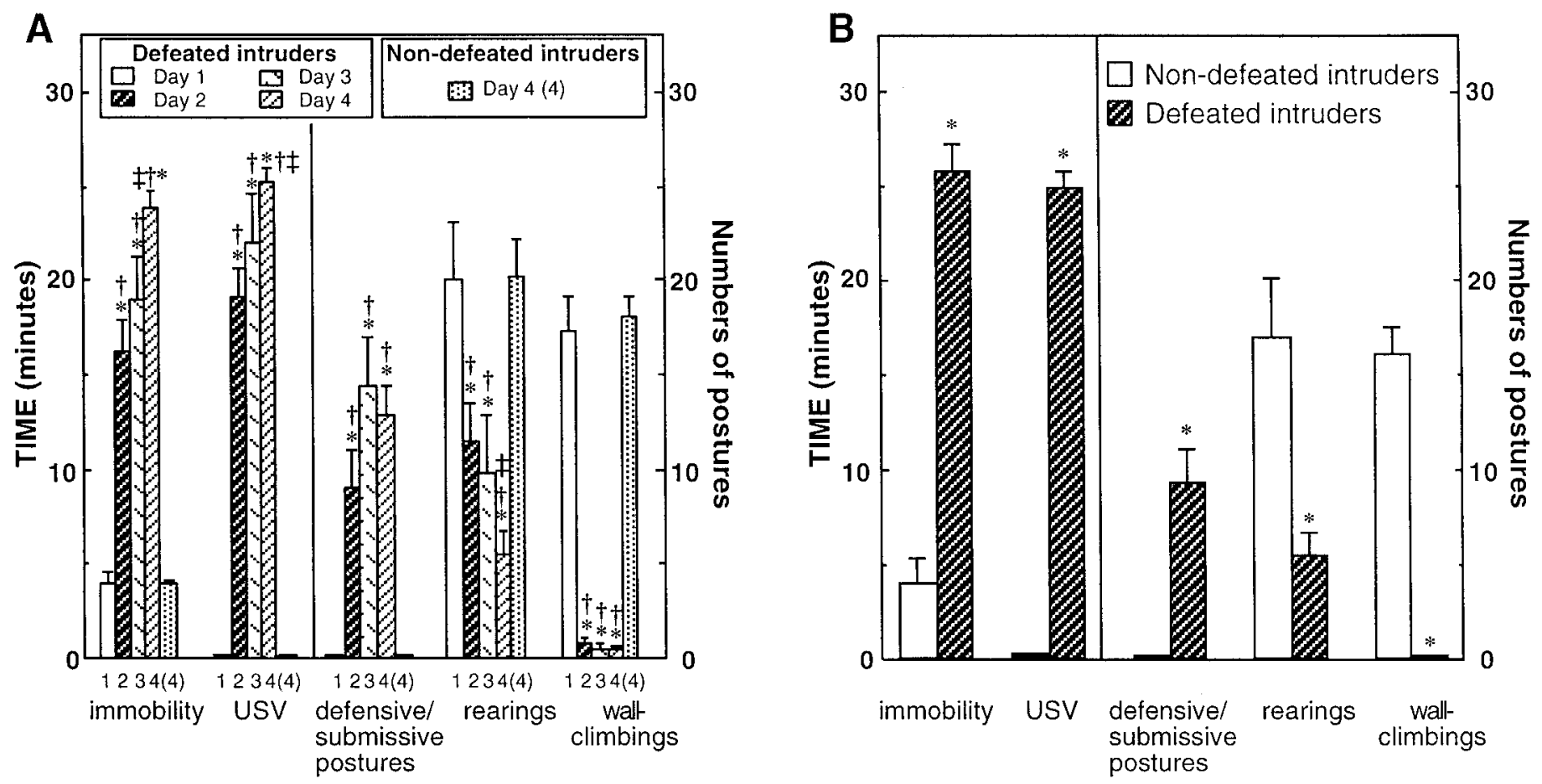

Figure 2. A, Behavioral responses of defeated rats during four consecutive conditioning sessions of social stress. Comparison with nondefeated intruders. Behavior of intruders was quantified during the $30 \mathrm{~min}$ period I of each conditioning session, when they were placed in a protective cage inside the home cage of residents (i.e., before removing the protective cage for $15 \mathrm{~min}$, period II). The duration of immobility and USV and the number of defensive-submissive postures, rearings, and wall-climbings were measured for the entire period I (30 min). No significant changes were noted between the successive sessions for nondefeated intruders; only the data corresponding to the fourth session [(4)] are shown. Data are the means \pm SEM of parameters recorded in eight defeated and six nondefeated intruders. ${ }^{*} p<0.01$ versus defeated intruders on day $1 ; \ddagger p<0.05$ versus defeated intruders on day $2 ; \dagger p<0.01$ versus nondefeated intruders on day 4. B. Effects of a 30 min protected exposure to resident rats during the microdialysis test session on the behavioral responses of defeated or nondefeated intruders. During the microdialysis experiment, i.e., on the ninth day of the protocol illustrated in Figure $1 B$, behavior of intruders was recorded for the $30 \mathrm{~min}$ protected exposure to residents. The five parameters were quantified as described above. Each bar is the mean \pm SEM of data obtained in eight defeated and six nondefeated intruders. ${ }^{*} p<0.01$ versus nondefeated intruders.

conditioning session and on the first day in both the to-be defeated and nondefeated intruders.

\section{Extracellular cortical levels of CCKLM in intruders}

The spontaneous CCKLM outflow (i.e., fractions 1-3 measured 120-30 min before exposure to resident) in defeated intruders was not significantly different from that measured in nondefeated intruders $(1.35 \pm 0.13 \mathrm{pg}$ of CCK equivalents per fraction; mean \pm SEM; $n=8$; vs $1.39 \pm 0.08 ; n=6$, respectively) (Fig. 3).

When defeated intruders were placed into the protective cage inside the home cage of the resident, a significant elevation of CCKLM extracellular levels was observed in the corresponding (fifth) microdialysate fraction $(+99 \pm 12 \% ; p<0.001 ; n=8)$. Subsequently, CCKLM levels returned to basal values and remained stable until the end of the experiment. In nondefeated intruders, introduction into the home cage of the resident did not significantly modify cortical CCKLM outflow.

\section{Effects of diazepam, buspirone, or $\mathrm{Cl}-988$ on behavior and extracellular CCKLM levels}

\section{Behavior}

Injection of saline or suspension of acacia gum in distilled water, $30 \mathrm{~min}$ before the $30 \mathrm{~min}$ protected confrontation, did not significantly affect the behavior of both defeated and nondefeated intruders compared with noninjected intruders (Table 1, Fig. 2B).

In nondefeated intruders, diazepam $(5 \mathrm{mg} / \mathrm{kg}$, i.p.) significantly decreased the number of rearings and wall-climbings and lengthened immobility time. These effects were completely prevented by flumazenil (10 mg/kg, i.p., 5 min before diazepam), which, on its own, significantly affected none of the five behavioral parameters measured (data not shown). Similarly, CI-988 (2 mg/kg, i.p.) (Table 1) and buspirone at three different doses (0.5, 1.0 and 2.0 $\mathrm{mg} / \mathrm{kg}$, i.p., $30 \mathrm{~min}$ before the protected confrontation) (data not shown) did not significantly change these parameters.

In defeated intruders, diazepam significantly reduced the duration of USV and the number of submissive-defensive postures, whereas the numbers of wall-climbings and rearings were increased when compared with acacia gum-injected intruders. These effects were completely prevented by flumazenil (Table 1), which, on its own, affected none of the five behavioral parameters quantified in the defeated intruders (data not shown). The CCK-B receptor antagonist CI-988 significantly reduced the time spent immobile and vocalizing, as well as the number of defensive-submissive postures, and enhanced rearings and wallclimbings (Table 1). Indeed, for defeated intruders treated with diazepam or CI-988, the values of all the measured parameters were not significantly different from those recorded in their nondefeated counterparts (except the duration of vocalization in CI-988-treated animals) (Table 1). In contrast, buspirone (0.5, 1.0 , and $2.0 \mathrm{mg} / \mathrm{kg}$, i.p.) did not significantly alter any of the five behavioral parameters in defeated intruders (data not shown).

\section{Extracellular cortical levels of CCKLM in intruders}

In both nondefeated (data not shown) and defeated intruders, neither saline, acacia gum, diazepam, buspirone, nor CI-988 


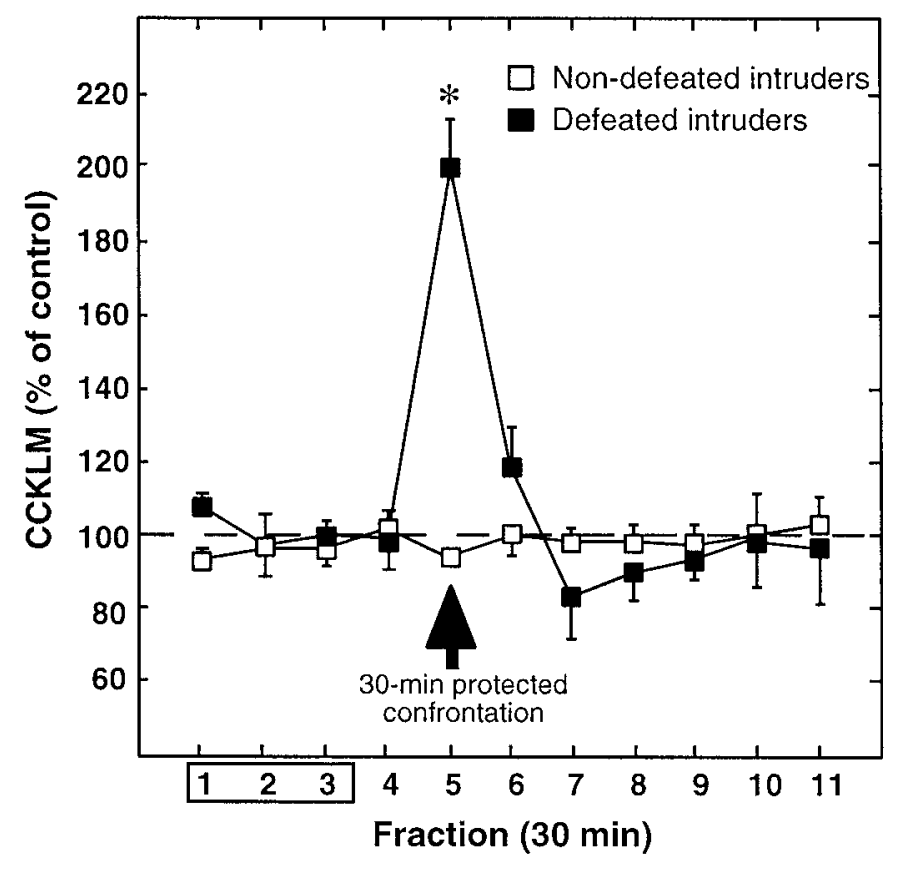

Figure 3. Effects of a 30 min protected exposure to residents on extracellular cortical levels of CCKLM in defeated or nondefeated intruders. Cortical CCKLM levels were measured for $120 \mathrm{~min}$ before, during (fraction 5), and $180 \mathrm{~min}$ after the $30 \mathrm{~min}$ exposure (arrow) of defeated $(n=8 ; \square)$ or nondefeated $(n=6 ; \square)$ intruders to residents. Data are the means \pm SEM of CCKLM contents of collected fractions, expressed as percentages of basal values, taken as the mean of fractions $1-3$. Fraction 1 is the first fraction collected after a 90 min washout period after probe insertion. ${ }^{*} p<0.001$ with respect to basal values.

affected the extracellular cortical levels of CCKLM before the protected confrontation to the resident (fraction 4) (Fig. 4).

In defeated intruders, acacia gum or saline did not modify stress-induced CCKLM overflow (compare Figs. 3, 4A,B). In contrast, diazepam completely abolished the increase in CCKLM contents in the fraction (fifth) collected during the 30 min protected confrontation to the resident (Fig. 4A). As illustrated in Figure $4 A$, flumazenil pretreatment (inactive on its own) (data not shown) prevented the effect of diazepam, and stress-induced CCKLM overflow in defeated intruders treated with the combination of these two drugs did not significantly differ from that measured in defeated intruders injected with the vehicle only. Similarly, CCKLM overflow was unaltered in defeated intruders treated with either CI-988 (Fig. $4 A$ ) or buspirone (at 0.5, 1.0, and $2.0 \mathrm{mg} / \mathrm{kg}$ ) (Fig. 4B) compared with vehicle-treated defeated intruders.

\section{DISCUSSION}

The present study shows that the anticipation of social defeat increased cortical CCKergic neurotransmission in rats. This effect seems in relation to stress and/or anxiety because the protocol used herein produced behaviors that could be related to this state. Moreover, the increase of cortical extracellular levels, as well as the anxiety-related behaviors, could be prevented by the potent anxiolytic drug diazepam, whereas the CCK-B receptor antagonist CI-988 reduced the behaviors only. That the $5-\mathrm{HT}_{1 \mathrm{~A}}$ receptor agonist buspirone had no effect on behavioral responses and CCKLM release associated with anticipation of social defeat suggests that this drug did not possess anxiolytic properties in this paradigm. All of these data show the existence of a close paral-
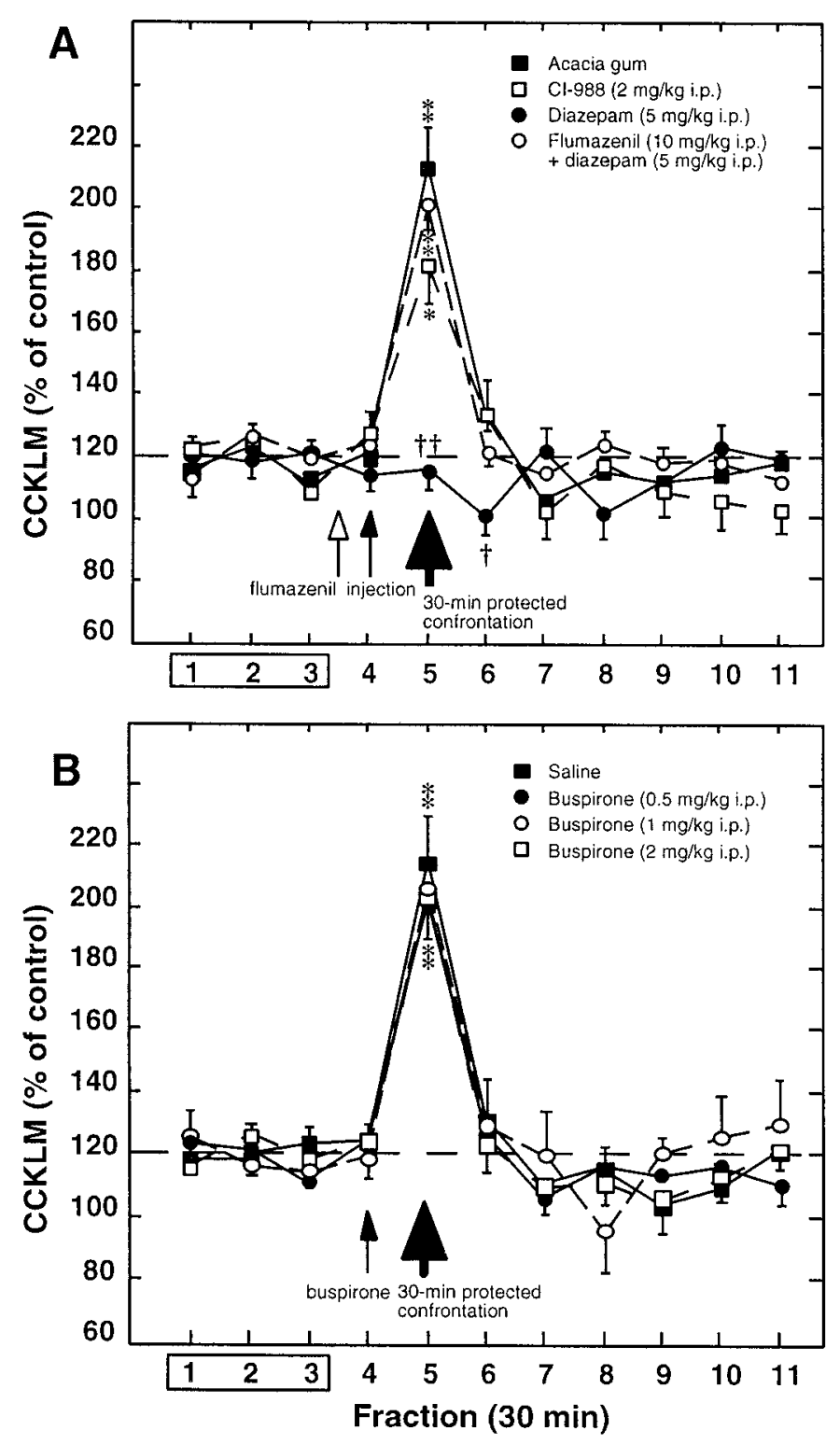

Figure 4. Effects of diazepam ( \pm flumazenil), buspirone, or CI-988 on cortical CCKLM outflow in defeated intruders subjected to a $30 \mathrm{~min}$ protected exposure to residents. $A$, Diazepam $(5 \mathrm{mg} / \mathrm{kg}$, i.p.; $n=8 ; \bullet)$, CI-988 $(2 \mathrm{mg} / \mathrm{kg}$, i.p.; $n=10 ; \square)$, or acacia gum $(n=7$; $)$ was administered (small filled arrow) $30 \mathrm{~min}$ before the $30 \mathrm{~min}$ protected exposure to residents (corresponding to fraction 5; large filled arrow). Flumazenil $(10 \mathrm{mg} / \mathrm{kg}$, i.p.; $n=6$; $\bigcirc)$ was administered $5 \mathrm{~min}$ before diazepam. $B$, Buspirone $[0.5 \mathrm{mg} / \mathrm{kg}(n=6 ; \bigcirc), 1.0 \mathrm{mg} / \mathrm{kg}(n=10 ; \bigcirc)$, or $2.0 \mathrm{mg} / \mathrm{kg}(n=6 ; \square)]$ or saline $(n=7 ; \square)$ was injected intraperitoneally 30 min before the $30 \mathrm{~min}$ protected exposure to residents. Data are the means \pm SEM of CCKLM contents of collected fractions, expressed as percentages of basal values, taken as the mean of fractions 1-3. Fraction 1 is the first sample collected after a 90 min wash-out period after probe insertion. ${ }^{*} p<0.01 ;{ }^{* *} p<0.001$ with respect to basal values $(100 \%)$. $\dagger p<$ $0.05 ; \dagger p<0.001$ with respect to corresponding values for defeated intruders given acacia gum.

lelism between the activation of cortical CCKergic neurotransmission and stress and/or anxiety-driven behavior in defeated rats.

The experimental procedure used in the present study was essentially based on that described by Miczek and his coworkers (Tornatzky and Miczek, 1994; Tidey and Miczek, 1996), who 
Table 1. Effects of diazepam, flumazenil plus diazepam, or CI-988 on the behavioral responses of nondefeated (ND) or defeated (D) intruders during a 30 min protected exposure to a resident, in the course of the microdialysis test session

\begin{tabular}{|c|c|c|c|c|c|}
\hline & & $\begin{array}{l}\text { Acacia gum } \\
(n=7)\end{array}$ & $\begin{array}{l}\text { Diazepam } \\
(5 \mathrm{mg} / \mathrm{kg}) \\
(n=8)\end{array}$ & $\begin{array}{l}\text { Flumazenil }(10 \mathrm{mg} / \mathrm{kg}) \\
\text { plus } \\
\text { diazepam }(5 \mathrm{mg} / \mathrm{kg}) \\
(n=6)\end{array}$ & $\begin{array}{l}\text { CI-988 } \\
(2 \mathrm{mg} / \mathrm{kg}) \\
(n=10)\end{array}$ \\
\hline \multirow[t]{2}{*}{ Immobility (minutes) } & ND & $4.23 \pm 0.90$ & $21.83 \pm 1.75^{\ddagger}$ & $4.42 \pm 0.30^{B}$ & $5.85 \pm 1.51$ \\
\hline & $\mathrm{D}$ & $25.14 \pm 1.13^{\dagger \dagger}$ & $25.40 \pm 0.57$ & $24.09 \pm 1.09^{\dagger \dagger}$ & $6.89 \pm 1.86^{* *}$ \\
\hline \multirow{2}{*}{ USV (minutes) } & ND & 0 & $0.86 \pm 0.53$ & 0 & 0 \\
\hline & $\mathrm{D}$ & $25.35 \pm 1.08^{\dagger \dagger}$ & $3.69 \pm 2.60^{* *}$ & $22.50 \pm 1.24^{\dagger+\infty+\infty \infty}$ & $7.47 \pm 1.60^{* * \dagger}$ \\
\hline \multirow{3}{*}{$\begin{array}{l}\text { Defensive-submissive postures } \\
\text { (numbers per } 30 \mathrm{~min} \text { ) }\end{array}$} & & & & & \\
\hline & ND & 0 & 0 & 0 & 0 \\
\hline & $\mathrm{D}$ & $10.00 \pm 1.53^{\dagger}$ & $0.67 \pm 0.33^{* *}$ & $8.50 \pm 1.60^{\dagger \infty}$ & $4.75 \pm 2.21^{*}$ \\
\hline \multirow[t]{2}{*}{ Rearings (numbers per $30 \mathrm{~min}$ ) } & ND & $18.28 \pm 2.13$ & $8.60 \pm 1.21^{\ddagger}$ & $19.33 \pm 2.40^{\beta}$ & $19.61 \pm 2.30$ \\
\hline & $\mathrm{D}$ & $4.05 \pm 0.44^{\dagger \dagger}$ & $8.33 \pm 0.58^{*}$ & $4.25 \pm 0.76^{\dagger+\infty}$ & $23.81 \pm 4.40^{* *}$ \\
\hline \multicolumn{6}{|l|}{ Wall-climbings (numbers per } \\
\hline \multirow[t]{2}{*}{$30 \mathrm{~min})$} & ND & $17.62 \pm 1.86$ & $3.22 \pm 1.33^{\ddagger}$ & $17.67 \pm 1.20^{\beta}$ & $17.54 \pm 1.82$ \\
\hline & $\mathrm{D}$ & $0^{\dagger \dagger}$ & $3.17 \pm 0.60^{*}$ & $0.25 \pm 0.25^{\dagger+\infty}$ & $15.60 \pm 1.62 * *$ \\
\hline
\end{tabular}

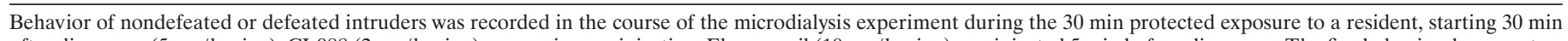

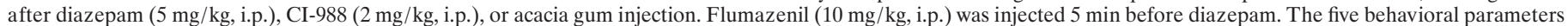
were quantified as indicated in the legend to Figure 2. Data are the means \pm SEM of data obtained in $n(6-10)$ rats.

$\stackrel{\ddagger}{p}<0.01$ versus nondefeated intruders given acacia gum.

${ }^{\dagger} p<0.05,{ }^{\dagger} p<0.01$ versus nondefeated intruders given the same treatment.

${ }^{\infty} p<0.05,{ }^{\infty \infty} p<0.01$ defeated intruders treated with flumazenil plus diazepam versus defeated intruders given diazepam.

${ }^{*} p<0.05,{ }^{*} p<0.01$ versus defeated intruders given acacia gum.

${ }^{B} p<0.01$ nondefeated intruders treated with flumazenil plus diazepam versus nondefeated intruders given diazepam.

established that the paradigm consisting of confrontations between an intruder and a resident rat on 4 consecutive days represents a social stress that offers the advantages of ecological and ethological validity. The major difference that we introduced in this paradigm is the timeline during the four conditioning sessions. In the procedure described by Miczek and his coworkers, intruders were placed in a protective cage after the defeat, whereas, in the present study, the 30 min protected session always preceded the defeat. Therefore, this procedure allowed us to investigate the anticipation of the defeat (psychosocial stress).

During the first exposure of the intruder, in a protective cage, to the resident, the intruder clearly displayed exploratory behavior as evidenced by numerous rearings and wall-climbings. In contrast, from the second session onward, rats defeated during period II of the preceding session exhibited clear-cut changes in behavior; rearings progressively declined and wall-climbings almost completely disappeared, whereas the immobility time progressively lengthened. In addition, the defeated intruders adopted defensive-submissive postures and emitted USV for a long duration. In rats subjected to the same protected confrontation, but not to the physical defeat by the resident (nondefeated intruders), none of the locomotor or social behaviors significantly changed throughout the five successive social encounters. In defeated intruders, the reduction of exploratory behavior cannot be accounted for by habituation because it was not observed in nondefeated intruders. During agonistic encounters with the resident animals (period II), the defeated intruders emitted USV in conjunction with defensive and submissive behavior (data not shown). In contrast, no USV were recorded before the first defeat. The appearance of USV in period I as soon as on the second conditioning session emphasizes the importance of the socially relevant context to generate USV. USV, particularly at low frequency $(20-30 \mathrm{kHz})$, are emitted in response to various anxiogenic events, including social defeat (Sales, 1972; de Vry et al., 1993; Vivian and Miczek, 1993; Tornatzky and Miczek, 1994).
In line with this interpretation, Blanchard et al. (1991) reported that the presentation of a cat to a rat led the latter to produce USV $(22 \mathrm{kHz})$ that occurred over the same period as freezing. On the other hand, previous studies (Vivian and Miczek, 1993; Tornatzky and Miczek, 1994) established that defensive-submissive postures can be related to state of fear and/or anxiety.

The behavior exhibited by the defeated intruders during the anticipation of defeat on the fifth experimental session did not significantly differ from that noted on the fourth confrontation session performed $4 \mathrm{~d}$ before. Indeed, on the microdialysis day, the protected confrontation of the intruders to the resident resulted in submissive-defensive postures, USV, and almost complete suppression of motor or exploratory behavior. These behaviors were associated with a marked increase in extracellular CCKLM levels in the frontal cortex. This effect lasted for the 30 min confrontation only, because CCKLM outflow returned to the baseline value and remained stable thereafter, up to the end of the experiment. In nondefeated intruders, neither behavior nor extracellular CCKLM levels were affected by the protected confrontation to the residents. This strongly suggests that the behavioral responses and the increase in cortical CCKLM outflow in defeated intruders could be attributed to the anticipatory "fear" of encountering an animal that had previously attacked and defeated them.

We have shown previously that exposure to other uncontrollable aversive stimuli, such as restraint stress, yohimbine administration, or ether inhalation, induced an increase in cortical CCKLM release in rats (Nevo et al., 1996; Becker et al., 1999). In the present study, the fact that the enhanced CCKLM outflow was observed during the anticipatory phase of a defeat episode and was abolished by the established anxiolytic diazepam further strengthens the anxiety-like interpretation of the situation. Furthermore, diazepam treatment also produced a marked decrease in the vocalization time and the number of defensive-submissive postures and an increased number of rearings and wall-climbings. 
These effects were actually attributable to the stimulation of benzodiazepine receptors because they were prevented by the benzodiazepine receptor antagonist flumazenil at a dose (10 $\mathrm{mg} / \mathrm{kg}$, i.p.) that blocks diazepam-induced behaviors (Ida et al., 1985; Rowlett and Woolverton, 1996; Matto et al., 1997). In line with the present data, diazepam, reported to act on the motivational or threat intensity dimension, was already shown to reduce vocalization in the Fear/Defense Test Battery (Blanchard et al., 1990) and in a social stress paradigm in rats (Tornatzky and Miczek, 1991). The fact that the increased time spent immobile in defeated intruders was not reversed by diazepam might be accounted for by the sedative effect of this benzodiazepine (Haefely et al., 1981). Accordingly, immobility was clearly lengthened in nondefeated intruders given diazepam, and this effect could be prevented by flumazenil.

In contrast to diazepam, the $5-\mathrm{HT}_{1 \mathrm{~A}}$ receptor agonist buspirone, at doses (0.5-2.0 mg/kg, i.p.) known to possess anxiolytic properties in some paradigms (Griebel, 1995), prevented neither the behavioral manifestations nor the enhancement of cortical extracellular CCKLM levels that accompanied the anticipation of a defeat episode. The lack of effect of buspirone on both behavioral and biochemical parameters indicated that the increased release of CCK did not result from some excitatory influence of 5-HT acting at 5- $\mathrm{HT}_{1 \mathrm{~A}}$ receptors. We showed previously that buspirone $(1 \mathrm{mg} / \mathrm{kg}$, i.p.) counteracted the increase in cortical extracellular CCKLM levels induced by restraint stress or administration of the anxiogenic compound yohimbine (Becker et al., 1999). This would indicate that the anxiolytic-like effects of $5-\mathrm{HT}_{1 \mathrm{~A}}$ receptor agonists depend on the anxiogenic-stress procedure used and sustains the opinion that conflict paradigms are less sensitive to the action of these compounds than unconditioned models (Griebel, 1995).

To investigate whether CCKLM overflow could be responsible, at least partly, for the behavioral responses in defeated intruders during the 30 min protected exposure to the resident, we attempted to prevent these responses by blocking CCK receptors. Although CI-988 has rather poor bioavailability and blood-brain barrier permeability, we chose this antagonist because it possesses a nanomolar affinity for CCK-B receptors and exhibits a good selectivity for CCK-B over CCK-A receptors (Noble et al., 1999). Indeed, numerous convergent studies previously demonstrated that the anxiogenic effects of CCK are mediated through the stimulation of CCK-B receptors (see references in the introductory remarks). The administration of CI-988 affected neither the spontaneous outflow of CCKLM nor the stress-induced CCKLM overflow in the frontal cortex of intruders, thereby suggesting that CCK release from CCKergic terminals may not be controlled by CCK autoreceptors. However, CI-988 markedly reduced all of the anxiety-like behaviors in defeated intruders. Thus, among the five parameters measured, only USV duration did not return to control values in CI-988-pretreated animals. Indeed, although still longer than in nondefeated intruders, the duration of USV was significantly reduced in CI-988-pretreated compared with nontreated defeated intruders. At the dose used in our studies, 2 $\mathrm{mg} / \mathrm{kg}$ intraperitoneally, CI-988 exerts clear-cut anxiolytic-like effects in various paradigms (Singh et al., 1991; Izumi et al., 1996; Adamec et al., 1997). Accordingly, the present results further support the idea that the activation of cortical CCKergic neurotransmission closely paralleled stress- and/or anxiety-driven behaviors in rats. It can be reasonably assumed that CCK itself contributed to these behaviors because they could be significantly reduced by the blockade of the actions of the peptide by CI-988.
In conclusion, the present study showed that anticipation of social defeat produces an anxiety-like state that is associated with an increase in cortical CCKergic neurotransmission. Furthermore, the latter event appeared to be probably involved in the genesis of anxiety-like behaviors. The experimental paradigm used herein should be suitable for both investigating the implication of other neuronal systems in anticipatory fear and assessing the potential anxiolytic properties of drugs.

\section{REFERENCES}

Adamec RE, Shallow T, Budgel J (1997) Blockade of $\mathrm{CCK}_{\mathrm{B}}$ but not $\mathrm{CCK}_{\mathrm{A}}$ receptors before and after the stress of predator exposure prevents lasting increases in anxiety-like behavior: implications for anxiety associated with posttraumatic stress disorder. Behav Neurosci 111:435-449.

Albonetti ME, Farabollini F (1994) Social stress by repeated defeat: effects on social behaviour and emotionality. Behav Brain Res 62:187-193.

Becker C, Hamon M, Benoliel J-J (1999) Prevention by 5-HT HA $_{\text {A }}$ receptor agonists of restraint stress- and yohimbine-induced release of cholecystokinin in the frontal cortex of the freely moving rat. Neuropharmacology 38:525-532.

Beinfeld MC, Meyer DK, Eskay RL, Jensen RT, Brownstein MJ (1981) The distribution of cholecystokinin immunoreactivity in the central nervous system of the rat as determined by radioimmunoassay. Brain Res 212:51-57.

Benoliel J-J, Bourgoin S, Mauborgne A, Pohl M, Legrand JC, Hamon M, Cesselin F (1992) GABA, acting at both $\mathrm{GABA}_{\mathrm{A}}$ and $\mathrm{GABA}_{\mathrm{B}}$ receptors, inhibits the release of cholecystokinin-like material from the rat spinal cord in vitro. Brain Res 590:255-262.

Blanchard DC, Blanchard RJ, Rodgers RJ (1990) Pharmacological and neural control of anti-predator defense in the rat. Aggress Behav $16: 165-175$.

Blanchard RJ, Blanchard DC, Agullana R, Weiss SM (1991) Twentytwo $\mathrm{kHz}$ alarm cries to presentation of a predator, by laboratory rats living in visible burrow systems. Physiol Behav 50:967-972.

Bradwejn J, Koszycki D, Meterissian G (1990) Cholecystokinin tetrapeptide induces panic attacks in patients with panic disorder. Can J Psychiatry 35:83-85.

Bradwejn J, Koszycki D, Couëtoux du Tertre A, van Megen H, den Boer J, Westenberg H, Annable L (1994) The panicogenic effects of cholecystokinin-tetrapeptide are antagonized by L-365,260, a central cholecystokinin receptor antagonist, in patients with panic disorder. Arch Gen Psychiatry 51:486-493.

Brodin K, Rosen A, Iwarsson K, Ogren SO, Brodin E (1989) Increased levels of substance-P and cholecystokinin in rat cerebral cortex following repeated electroconvulsive shock and subchronic treatment with serotonin uptake inhibitor. Acta Physiol Scand 136:613-614.

Daugé V, Léna I (1998) CCK in anxiety and cognitive processes. Neurosci Biobehav Rev 22:815-825.

de Montigny C (1989) Cholecystokinin-tetrapeptide induces panic-like attacks in healthy volunteers. Arch Gen Psychiatry 46:511-517.

de Vry J, Benz U, Schreiber R, Traber J (1993) Shock-induced ultrasonic vocalization in young adult rats: a model for testing putative antianxiety drugs. Eur J Pharmacol 249:331-339.

Griebel G (1995) 5-Hydroxytryptamine-interacting drugs in animal models of anxiety disorders: more than 30 years of research. Pharmacol Ther 65:319-395.

Haefely W, Pieri L, Polc P, Schaffner R (1981) General pharmacology and neuropharmacology of benzodiazepine derivatives. In: Handbook of experimental pharmacology (Hoffmeister F, Stille G, eds), pp 13262. Berlin: Springer.

Hamon M (1997) The main features of central 5-HT $\mathrm{HT}_{1 \mathrm{~A}}$ receptors. In: Serotoninergic neurons and 5-HT receptors in the CNS. In: Handbook of Experimental Pharmacology (Baumgarten HG, Göthert M, eds), pp 239-268. Berlin: Springer.

Harro J, Kiivet R-A, Lang A, Vasar E (1990) Rats with anxious or non-anxious type of exploratory behaviour differ in their brain CCK-8 and benzodiazepine receptor characteristics. Behav Brain Res 39:63-71.

Harro J, Jossan SS, Oreland L (1992) Changes in cholecystokinin receptor binding in rat brain after selective damage of the locus coeruleus projections by DSP-4 treatment. Naunyn Schmiedebergs Arch Pharmacol 364:425-431.

Hughes J, Boden P, Costall B, Domeney A, Kelly E, Horwell DC, Hunter JC, Pinnock RD, Woodruff GN (1990) Development of a class of selective cholecystokinin type $\mathrm{B}$ receptor antagonists having potent anxiolytic activity. Proc Natl Acad Sci USA 87:6728-6732.

Hunkeler W, Mohler H, Pieri L, Polc P, Bonetti EP, Cumin R, Schaffner R, Haefely W (1981) Selective antagonists of benzodiazepines. Nature 290:514-516. 
Iadarola MJ, Naranjo JR, Duchemin AM, Quach TT (1989) Expression of cholecystokinin and enkephalin mRNA in discrete brain regions. Peptides 10:687-692.

Ida Y, Tanaka M, Tsuda A, Tsujimaru S, Nagasaki N (1985) Attenuating effect of diazepam on stress-induced increases in noradrenaline turnover in specific brain regions of rats: antagonism by Ro 15-1788. Life Sci 37:2491-2498.

Izumi $\mathrm{T}$, Inoue $\mathrm{T}$, Tsuchiya $\mathrm{K}$, Hashimoto $\mathrm{S}$, Ohmori $\mathrm{T}$, Koyama $\mathrm{T}$ (1996) Effect of the selective CCKB receptor antagonist LY288513 on conditioned fear stress in rats. Eur J Pharmacol 300:25-31.

Keeney AJ, Hogg S (1999) Behavioural consequences of repeated social defeat in the mouse: preliminary evaluation of a potential animal model of depression. Behav Pharmacol 10:753-764.

Koolhaas JM, Hermann PM, Kemperman C, Bohus B, van den Hoofdakker RH, Beersma DGM (1990) Single social defeat in male rats induces a gradual but long lasting behavioural change: a model of depression? Neurosci Res Commun 7:35-41.

Koolhaas JM, Meerlo P, De Boer SF, Strubbe JH, Bohus B (1997) The temporal dynamics of the stress response. Neurosci Biobehav Rev 6:775-782.

Marley PD, Rehfeld JF, Emson PC (1984) Distribution and chromatographic characterisation of gastrin and cholecystokinin in the rat central nervous system. J Neurochem 42:1523-1535.

Matto V, Harro J, Allikmets L (1997) The effects of cholecystokinin A and $\mathrm{B}$ receptor antagonists on exploratory behaviour in the elevated zero-maze in rat. Neuropharmacology 36:389-396.

Miczek KA, Thompson ML, Tornatzky W (1991) Subordinate animals: behavioral and physiological adaptations and opioid tolerance. In: Neurobiology of stress (Brown MR, Koob GF, Rivier C, eds), pp 323-357. New York: Dekker.

Nevo I, Becker C, Hamon M, Benoliel J-J (1996) Stress- and yohimbineinduced release of cholecystokinin in the frontal cortex of freely moving rat: prevention by diazepam but not ondansetron. J Neurochem 66:2041-2049.

Noble F, Wank SA, Crawley JN, Bradwejn J, Seroogy KB, Hamon M, Roques BP (1999) International Union of Pharmacology. XXI. Structure, distribution, and functions of cholecystokinin receptors. Pharmacol Rev 51:745-781.
Paxinos P, Watson C (1986) The rat brain in stereotaxic coordinates, Ed 2. Sydney: Academic.

Rowlett JK, Woolverton WL (1996) Assessment of benzodiazepine receptor heterogeneity in vivo: apparent $\mathrm{pA} 2$ and $\mathrm{pKB}$ analyses from behavioral studies. Psychopharmacology 128:1-16.

Sales GD (1972) Ultrasound and aggressive behaviour in rats and other small mammals. Anim Behav 20:88-100.

Shlick J, Vasar E, Bradwejn J (1997) Cholecystokinin and psychiatric disorders. Role in aetiology and potential of receptor antagonists in therapy. Cent Nerv Syst Drugs 8:134-152.

Siegel RA, Düker EM, Fuchs E, Pahnke U, Wuttke W (1984) Responsiveness of mesolimbic, mesocortical, septal and hippocampal cholecystokinin and substance-P neuronal systems to stress, in the male rat. Neurochem Int 6:783-789.

Singh L, Field MJ, Hughes J, Menzies R, Oles RJ, Vass CA, Woodruff GN (1991) The behavioural properties of CI-988, a selective cholecystokinin $_{\mathrm{B}}$ receptor antagonist. Br J Pharmacol 104:239-245.

Studler JM, Simon H, Cesselin F, Legrand JC, Glowinski J, Tassin JP (1981) Biochemical investigation on the localization of the cholecystokinin octapeptide in dopaminergic neurons originating from the ventral tegmental area of the rat. Neuropeptides 2:131-139.

Tidey JW, Miczek KA (1996) Social defeat stress selectively alters mesocorticolimbic dopamine release: an in vivo microdialysis study. Brain Res 721:140-149.

Tornatzky W, Miczek KA (1991) Behavior and physiology of socially stressed rats: anti- and pro-stress effects of anxiolytics. Soc Neurosci Abstr 17:147.

Tornatzky W, Miczek KA (1994) Behavioral and autonomic responses to intermittent social stress: differential effects of clonidine and metoprolol. Psychopharmacology 116:346-356.

van Megen HJGM, Westenberg HGM, den Boer JA, Kahn RS (1996) Cholecystokinin in anxiety. Eur Neuropsychopharmacol 6:263-280.

Vasar E, Peuranen E, Harro J, Lang A, Oreland L, Männistö PT (1993) Social isolation of rats increases the density of cholecystokinin receptors in the frontal cortex and abolishes the anti-exploratory effect of caerulein. Naunyn Schmiedebergs Arch Pharmacol 348:96-101.

Vivian JA, Miczek KA (1993) Diazepam and gepirone selectively attenuate either $20-32 \mathrm{kHz}$ or $32-64 \mathrm{kHz}$ ultrasonic vocalizations during aggressive encounters. Psychopharmacology 113:66-73. 